\title{
An unusual cause of spontaneous pneumothorax
}

\author{
Dionisios Spyratos, ${ }^{1}$ Vasilios Kalpakidis, ${ }^{2}$ Paschalina Giouleka, ${ }^{1}$ Diamantis Chloros, ${ }^{1}$ Lazaros Sichletidis ${ }^{1}$
}

${ }^{1}$ Pulmonary Department, Aristotle University of Thessaloniki, Thessaloniki, Greece;

2Department of Interventional Radiology, 'G. Papanikolaou Hospital', Thessaloniki, Greece

Correspondence to Lazaros Sichletidis, sichlet@med.auth.gr

\section{Summary}

Bronchopulmonary sequestration is a congenital pulmonary malformation consisting of a non-functioning region of lung parenchyma that receives systemic arterial blood supply. The authors present the case of a 31-year-old male who presented with spontaneous pneumothorax as the initial clinical manifestation of an intralobar bronchopulmonary sequestration. There was a persistent air leak through the chest tube which remained in the pleural cavity for 12 days. CT revealed an area of increased opacity, with focal calcifications and a small eccentric cavity in the posterior basal region of the left lower lobe. Aortography established the final diagnosis.

\section{BACKGROUND}

Spontaneous pneumothorax as the initial manifestation of bronchopulmonary sequestration is extremely rare.

\section{CASE PRESENTATION}

A 31-year-old male presented (29 May 2010) to the emergency department of a regional hospital (Giannitsa, Pella, Greece) reporting chest pain on the left hemithorax of acute onset (a few hours before) and dyspnoea. He also reported symptoms (fever up to $38^{\circ} \mathrm{C}$, productive cough and myalgias) compatible with respiratory infection, during the past 4 days.

He was a non-smoker, was working as a teacher during the past 3 years, had no history of illegal drugs use or recent travel abroad and there was no use of any medical drug regularly. The patient reported an inconclusive diagnosis of a 'pulmonary cyst' based on a CT that was performed a few hours after a car accident 5 years ago.

Chest x-ray revealed pneumothorax on the left side (figure 1A), the patient was haemodinamically stable and a chest tube was immediately placed under local anaesthesia (figure $1 \mathrm{~B})$. The patient was febrile $\left(38.5^{\circ} \mathrm{C}\right.$ for 2 days after admission), white cell counts were elevated (15 000/ $\mathrm{mm}^{3}, 92 \%$ neutrophils) while $\mathrm{C}$ reactive protein (42 mg/dl) and procalcitonin $(2.8 \mu \mathrm{g} / \mathrm{l})$ were also increased. Sputum cultures revealed multiple microorganisms (Streptococcus pneumonia and mixed anaerobes without predominance) and an empirical therapy with intravenous ampicillin/sulbactam was given.

Two days later there was still air in the pleural cavity, as shown by the CT scan (figure 2A). Thoracic surgery team proposed suction via the chest tube $(-25$ to $-30 \mathrm{~cm}$ $\mathrm{H}_{2} \mathrm{O}$ ) for 7-10 days and follow-up with x-rays. There was no need for surgical intervention as full expansion of the left lung was achieved 5 days after admission and the chest tube was removed 12 days after placement in order to induce pleural adhesions via mechanical irritation. It should be noted that in the regional hospital of Giannitsa (Greece) there is no availability of video-assisted thoracoscopic surgery (VATS) in the surgical department.

Then the patient was referred to the pulmonary department of a tertiary hospital ('G. Papanikolaou' Hospital, Thessaloniki, Greece). Taking into account that the present case was a difficult-to-treat pneumothorax and
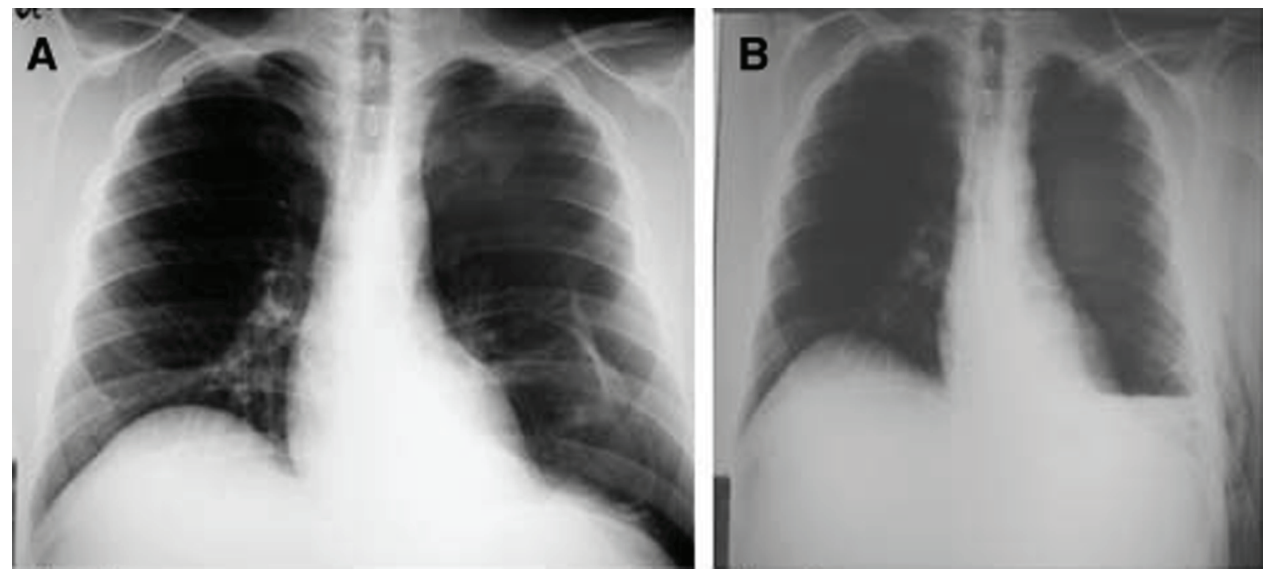

Figure 1 (A) Extensive pneumothorax on the left side and pleural thickenings on the lower pulmonary field. (B) Air-fluid level in the pleural cavity after insertion of the chest tube. 


\section{BMJ Case Reports}
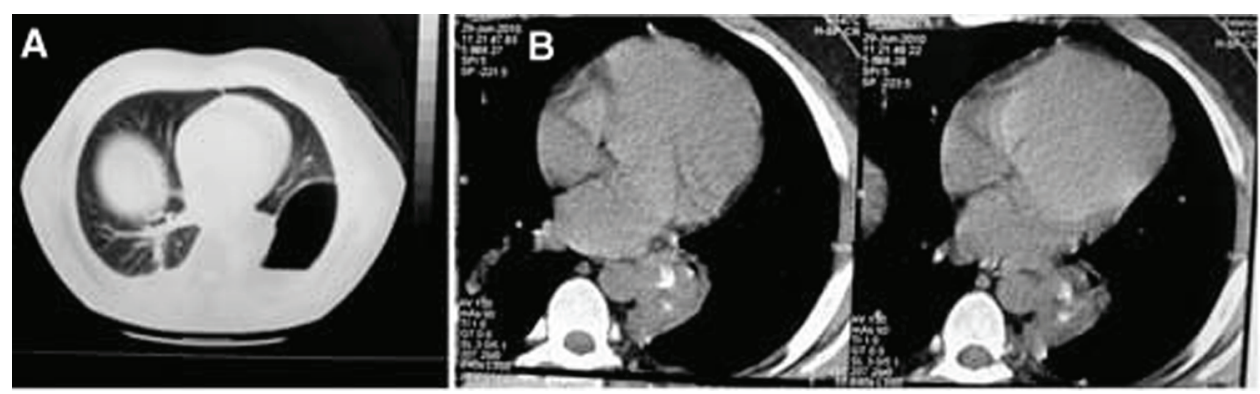

Figure 2 (A) Significant amount of air in the pleural cavity 2 days after chest tube placement. (B) CT scan 1 month later revealed a solid lesion with focal calcifications and a small eccentric cavity in the posterior basal segment of the left lower lobe.

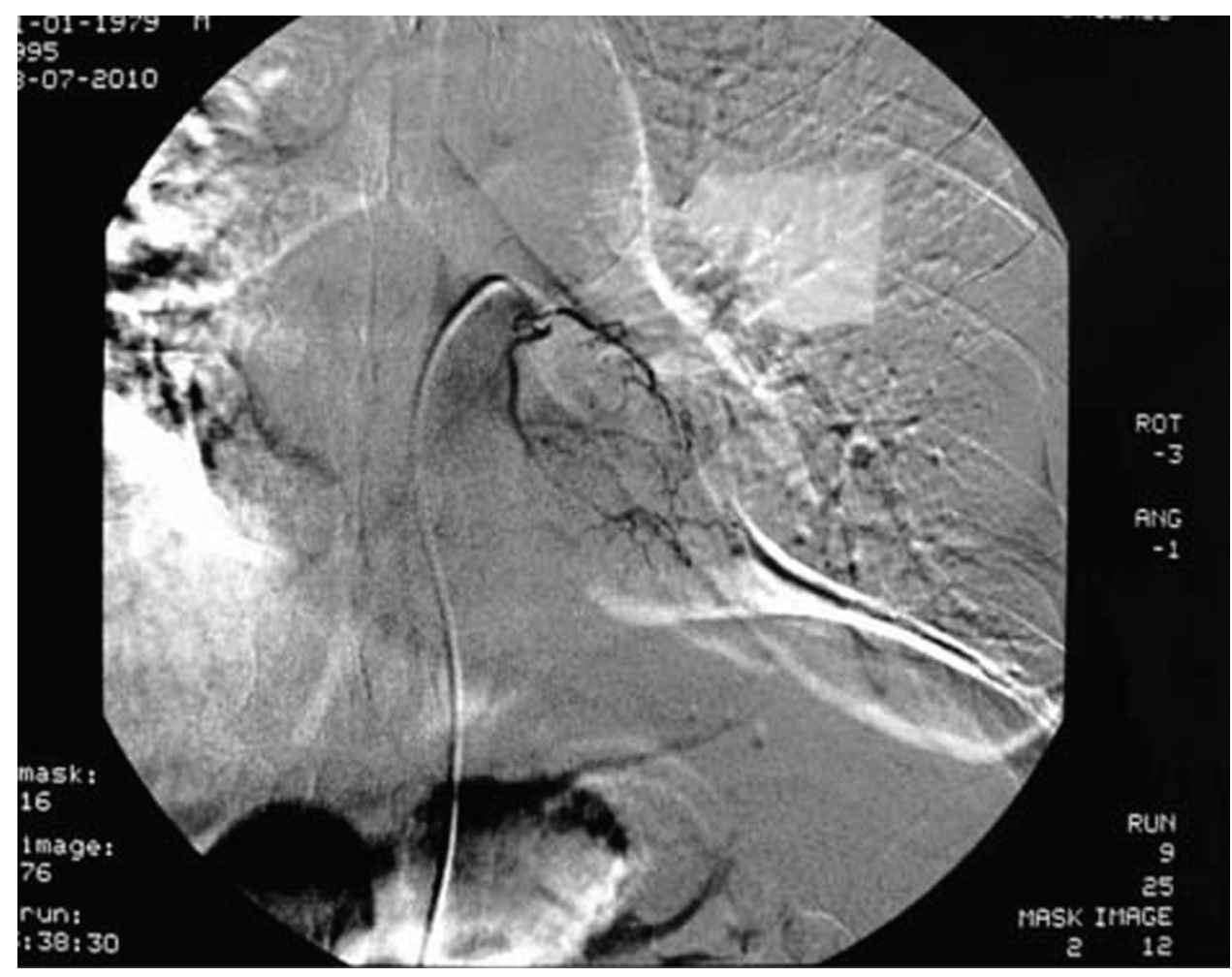

Figure 3 The aortographic study revealed supply of the lesion by two feeding arteries of the descending aorta. The feeding artery was located below the carina of the trachea.

the first CT scan was performed with pneumothorax so the underlying lesion could not be assessed in details, we decided to perform chest CT scan 1 month after the initial episode (figure 2B). It showed an area of increased opacity, with focal calcifications and a small eccentric cavity in the posterior basal region of the left lower lobe. We decided to perform aortography (figure 3) because the lesion was adjacent to the descending aorta while the possibility of malignancy was low. Our diagnosis was intralobar bronchopulmonary sequestration. We hypothesised that an infection leaded to inflammation and rupture of the intralobar sequestration which communicated with the normal lung parenchyma. There was no evidence of subpleural blebs in the apices.

\section{OUTCOME AND FOLLOW-UP}

We decided to follow-up the patient, not recommending surgical removal at this time as this was the first episode of pneumothorax, there was no history of recurrent lower respiratory infections or haemoptysis.

\section{DISCUSSION}

The present case refers to a young adult with possible secondary spontaneous pneumothorax due to bronchopulmonary sequestration. Direct identification of a ruptured site in bronchopulmonary sequestration would be possible if VATS was performed during the pneumothorax episode.

Persistent air leak is a common problem in these cases, the optimal time to refer the patient for surgical intervention (VATS) is unclear and treatment decisions should be made on an individual basis. Some retrospective studies showed that in patients with secondary spontaneous pneumothorax and persistent air leak, waiting with chest tube in place for 7-14 days was a reasonable approach as pneumothorax resolved without need for surgical intervention. ${ }^{12}$ 
Surgeons in the regional hospital decided to leave the chest tube for 7 days after full lung expansion as an alternative method to induce pleurodesis without using chemical agents (eg, talc). Even though there is no evidence in the literature for pneumothorax, some studies among patients with malignant pleural effusion proved that the presence of a pleural catheter is a quite effective method of inducing spontaneous pleurodesis. ${ }^{34}$

Bronchopulmonary sequestration is a congenital malformation in which a part of non-functioning pulmonary parenchyma with abnormal tracheobronchial branching retains its embryonic systemic vascular supply. The term 'sequestration' is characterised by an abnormal communication between the lesion and one or more of the four important components of normal lung tissue (airways, parenchyma, arterial supply and venous drainage). ${ }^{5}$ It accounts for 0.15 $6.4 \%$ of all congenital pulmonary abnormalities. ${ }^{6}$

If these lesions share the same visceral membrane with the normal lung are defined as intralobar (approximately 75\% of cases) or otherwise are considered extralobar. Intralobar sequestrations are almost always located within the lower lobes (approximately $2 / 3$ of cases on the left), in the paravertebral region of the posterior basal segment and are usually supplied by vessels that originate from the descending thoracic aorta (abdominal aorta is the second most common origin) and drain into the pulmonary veins. ${ }^{7}$ Location in the right upper lobe is a rare possibility. ${ }^{8}$ Other congenital abnormalities may accompany both intra- and extralobar sequestrations (most commonly diaphragmatic hernias).

Concerning intralobar sequestrations, diagnosis is usually established during late adolescence or early adulthood after recurrent lower respiratory infections. Initially the chest radiograph reveals lower lobe pneumonia while the sequestration becomes apparent after resolution of the infection related infiltrates. Haemoptysis is another clinical manifestation. ${ }^{9}$ A small percentage of patients are asymptomatic. Congestive heart failure due to left-left shunt as well as huge space-occupying cysts has been described in infancy or early childhood. ${ }^{7}$ Spontaneous pneumothorax resulting from rupture of a cyst is an extremely rare presentation. ${ }^{10}$

Generally, invasive angiography is considered the 'gold standard' for the diagnosis even though current non-invasive methods (multidetector CT or MR angiography) are highly sensitive with minimal radiation exposure. ${ }^{11}$ Although surgical removal by thoracotomy remains the treatment of choice, thoracoscopy is an acceptable alternative for intralobar sequestrations ${ }^{12}$ as well as embolisation. ${ }^{13}$

\section{Learning points}

- Spontaneous pneumothorax could be the initial clinical manifestation of an intralobar bronchopulmonary sequestration.

\section{Competing interests None.}

Patient consent Obtained.

\section{REFERENCES}

1. Chee CB, Abisheganaden J, Yeo JK, et al. Persistent air-leak in spontaneous pneumothorax-clinical course and outcome. Respir Med 1998;92:757-61.

2. Mathur R, Cullen J, Kinnear WJM, et al. Time course of resolution of persistent air leak in spontaneous pneumothorax. Respir Med 1995;89:129-32.

3. Tremblay A, Michaud G. Single-center experience with 250 tunnelled pleural catheter insertions for malignant pleural effusion. Chest 2006;129:362-8.

4. Putnam JB Jr, Walsh GL, Swisher SG, et al. Outpatient management of malignant pleural effusion by a chronic indwelling pleural catheter. Ann Thorac Surg 2000;69:369-75.

5. Clements BS, Warner JO. Pulmonary sequestration and related congenital bronchopulmonary-vascular malformations: nomenclature and classification based on anatomical and embryological considerations. Thorax 1987; 42:401-8.

6. Savic B, Birtel FJ, Tholen W, et al. Lung sequestration: report of seven cases and review of 540 published cases. Thorax 1979;34:96-101.

7. Fraser RS. Developmental anomalies affecting the airways and lung parenchyma. In: Fraser RS, Colman N, Müller NL, et al eds. Fraser and Pare's Diagnosis of Diseases of the Chest. Philadelphia, PA: W.B. Saunders 1999:595-637

8. Ferretti GR, Jouvan FB, Coulomb M. MDCT demonstration of intralobar pulmonary sequestration of the right upper lobe in an adult. AJR Am J Roentgenol 2005;185:1663-4

9. Rubin EM, Garcia H, Horowitz MD, et al. Fatal massive hemoptysis secondary to intralobar sequestration. Chest 1994;106:954-5.

10. Kilman JW, Battersby JS, Taybi H, et al. Pulmonary sequestration. Arch Surg 1965;90:648-57

11. Abbey P, Das CJ, Pangtey GS, et al. Imaging in bronchopulmonary sequestration. J Med Imaging Radiat Oncol 2009;53:22-31.

12. Kestenholz PB, Schneiter D, Hillinger S, et al. Thoracoscopic treatment of pulmonary sequestration. Eur J Cardiothorac Surg 2006;29:815-18.

13. Lee KH, Sung KB, Yoon HK, et al. Transcatheter arterial embolization of pulmonary sequestration in neonates: long-term follow-up results. J Vasc Interv Radiol 2003;14:363-7.

This pdf has been created automatically from the final edited text and images.

Copyright 2011 BMJ Publishing Group. All rights reserved. For permission to reuse any of this content visit

http://group.bmj.com/group/rights-licensing/permissions.

BMJ Case Report Fellows may re-use this article for personal use and teaching without any further permission.

Please cite this article as follows (you will need to access the article online to obtain the date of publication).

Spyratos D, Kalpakidis V, Giouleka P, Chloros D, Sichletidis L. An unusual cause of spontaneous pneumothorax. BMJ Case Reports 2011;

10.1136/bcr.08.2010.3209, date of publication

Become a Fellow of BMJ Case Reports today and you can

- Submit as many cases as you like

- Enjoy fast sympathetic peer review and rapid publication of accepted articles

- Access all the published articles

- Re-use any of the published material for personal use and teaching without further permission

For information on Institutional Fellowships contact consortiasales@bmjgroup.com

Visit casereports.bmj.com for more articles like this and to become a Fellow 